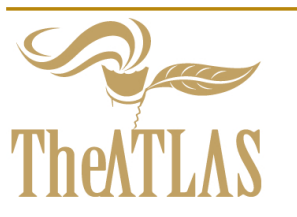

\title{
Transdisciplinarity and Consciousness: Toward an Integrated Model
}

\author{
Arthur Vers/uis ${ }^{1}$ and Basarab Nicolescu ${ }^{2},{ }^{1}$ Department of Religious Studies, College of Arts \& Letters \\ Michigan State University, MI, Email: arthur.versluis@gmail.com; ${ }^{2}$ International Center for Transdisciplinary Research and \\ Studies (CIRET), France, Email: basarab.nicolescu@gmail.com
}

Received 8 February 2018; Revised 20 March 2018; Accepted 22 March 2018

Copyright (C) 2018 Arthur Versluis and Basarab Nicolescu. This is an open access article distributed under the Creative Commons Attribution License (https://creativecommons.org/licenses/by/4.0/), which permits unrestricted use, distribution, and reproduction in any medium, provided the original work is properly cited.

Available online 23 March 2018 at www.atlas-journal.org, doi: 10.22545/2018/00098

\begin{abstract}
A
lthough there have been many advances in physics, the implications of quantum theories have not been incorporated into the humanities. As a result, much of academia has remained in a seventeenth or eighteenth century worldview, with some scholars still seeking to analyze spirituality in dualistic, reductionistic, and materialistic terms that in fact have been superceded. Such perspectives often result in mistaken thinking based in category errors. In this article, we point the way beyond such dualism, and argue in favor of transdisciplinary approaches to the study of religion and in particular, spirituality. We posit a new model for understanding interiority prefiguring a unified, transdisciplinary approach that engages quantum physics and the humanities.
\end{abstract}

Keywords: Transdisciplinarity, consciousness, integrative, humanities, quantum mechanics.

\section{Introduction}

Over the past century, there have been tremendous advances in the study and understanding of physics, as classical physics was followed by quantum theories. Contemporary quantum theories present cosmological insights that upend the way we previously understood the world. But the rest of academia has not yet fully come to grips with some of the implications of theoretical physics and the insights it offers. In fact, for the most part those of us in the humanities still see largely through dualistic Cartesian lenses fashioned in the seventeenth or eighteenth century. As we will see, such perspectives in fact result in mistaken thinking based in category errors. In this article, we will explore some implications of theoretical physics that will help us see the study of consciousness, and in particular what we will term interiority, in a new light.

First, however, some remarks on our use of terminology. In what follows, the word "transdisciplinarity" refers to the unity of knowledge beyond disci- 
plines, beyond also the artificial division between the hard sciences and the humanities. Transdisciplinarity is therefore not in conflict with but rather integrates and transcends disciplinary boundaries [1]. Transdisciplinarity (which emerged out of the discoveries of quantum physics and their implications for other fields of knowledge) is based in the recognition that there are levels of reality, understood both ontologically and epistemologically [2]. In other words, a law of physics that is valid on one level of reality (for instance, that of classical physics) may very well not be valid or applicable at all at another level of reality (for instance, at a quantum level).

At the same time, seen collectively, the different mathematical equations that comprise and inform contemporary models of physics are aimed at developing a more comprehensive map and understanding on different levels with the overarching goal of creating a deeper understanding of the nature of reality that incorporates different levels into a larger model. As Roger Penrose put it in The Road to Reality, broadly speaking across levels, mathematical truth is objectively true in that it represents "an objective external standard that is not dependent upon our individual opinions nor upon our particular culture" [3]. In this sense, mathematics provides insight into what can be described as a Platonic realm of truth.

But whereas in quantum physics there has been remarkable progress in developing extremely sophisticated models for understanding the nature of reality, those of us in the humanities have not caught up. As a result, there has been a growing disconnect between the sciences, particularly the realm of quantum physics, and the humanities. Transdisciplinarity, especially as developed in the works of Basarab Nicolescu and in the international association CIRET [Le Centre International de Recherches et Études Transdisciplinaires], is conceived as a way of bridging the chasm between the humanities and sciences in the quantum age and developing a unified epistemological model at a meta-level beyond particular disciplines.

In what follows we will apply transdisciplinary methodology to the contemporary study of consciousness, and our particular focus is on esoteric religion or spirituality. To do so, we must distinguish between the terms "religion" and "spirituality." Broadly speaking, religion has to do with socio-cultural phenomena, whereas spirituality has to do with meaning, values and inner life. Religion is thus to be understood as an object of study, while spirituality has to do with the subject that is transformed, transmuted, or awakened through spiritual practices like prayer, meditation, chanting, liturgy, and visualization. It should be evident that studying religion as object, for instance, as socio-cultural phenomena, is epistemologically different from subjective experiential reflective or introspective self-knowledge [4].

Our point here is not that one of these is valid and the other invalid. Rather, our point is that both perspectives are valid on their own terms. In other words, the study of religious phenomena in different cultural and social contexts, from more or less materialistic perspectives, provide insights that are complemented by understanding what we are here describing with the shorthand term "interiority," referring to the realm of meaning, subjective experience, and reflexive self-aware knowledge. Exteriority in this context refers to brain function. One can, for example, hear music without having an interior experience of it. Exteriority and interiority are not opposed to one another, but rather are complementary. However, many contemporary theories concerning religion, as well as methodologies for studying it, privilege dualistic, materialistic approaches as "scientific" and "empirical" while they denigrate or reject subjective experiential knowledge. What we are describing here (also designated as esoteric religion) may best be termed "interior spirituality" or "interiority" based in the union of subject and object in the practitioner. Externalism or exteriority does not require the union of subject and object in the practitioner - it is limited to an analysis of something conceived as an object.

Earlier notions of scientific method as concerned strictly with the dualistic separation of the ratiocinative mind from the materialistic objects of knowledge no longer fit our collective knowledge about the cosmos in the wake of quantum physics. The study of religion, and in particular of spirituality, must move forward into a twenty-first-century integrated model, and we argue transdisciplinarity provides the fundamental elements for such a new science of spirituality and, therefore, of consciousness. 


\section{The Failure of Reductive and Externalist Approaches}

Contemporary methodologies and theoretical models of religion for the most part belong to the world of classical logic, and to a scientific model of the seventeenth century-that is, they are governed by a fundamentally dualistic view of objective knowledge. In other words, the question of the subject is, ironically, taboo, as Alan Wallace has detailed in The Taboo of Subjectivity, and religion is held to be an object of study like any other, such as biology [5]. Durkheimian, Weberian, Marxian, even Geertzian approaches to the study of religion as semiotics share dualistic and materialistic assumptions concerning knowledge about religion that by and large are anti-transcendental and anathematize words like "spiritual," or "spirituality," let alone mysticism or gnosis.

The past several decades have seen more and more reductionist approaches to the study of religion. Exemplary of this development is the founding of the North American Association for the Study of Religion [NAASR], whose officers have included Russell McCutcheon, Willi Braun, Tomoko Masuzawa, William Arnal, Donald Wiebe, and others whose work collectively argues for "a genuine scientific/scholarly approach to the study of religion, free from religious influence [6]." A scientific approach here is conceived as the rejection of "religious influence" as well as what we are here terming interiority, often combined with a strong rejection of phenomenological or other approaches that seek to recognize and synthesize objective and subjective knowledge.

In the late twentieth and early twenty-first centuries, approaches to religion and religious phenomena developed in both cognitive science and neuroscience. However, both of these sets of approaches are also based in fundamentally dualistic methodologies. Underlying both cognitive scientific and neuroscientific approaches to religion typically are physicalist and functionalist models within which it is assumed that consciousness is epiphenomenal and mental activities deemed religious emerged from either evolutionary mechanisms (cognitive science) or from neurological phenomena (neuroscience) in which either mental actions/reactions or neurophysiological actions/reactions determine what we may term religious mental and physical activities. Thus, for instance, reacting to potential predators or agents in the environment conditions us to believe in such agents, ultimately conditioning us to believe in unseen agents, for instance, a monotheistic deity [7, 8, 9, 10]. Likewise, the neuroscientific approaches measure brain activity through functional Magnetic Resonance Imaging [fMRIs] or other mechanisms, again fundamentally a dualistic model based in the idea that, ironically, a subjective consciousness can develop an objective externalized model about itself without confronting the question of its own nature, which remains taboo. Of course another way to avoid most and perhaps nearly all questions that we are considering here is to attempt to side-step them by confining one's focus to "material history" of religion or "social history" of religion. But this is simply to ignore the larger questions.

Not atypical is Jan Platvoet, a former Catholic priest in Africa trained in missiology, later converted to being a proponent of ridding Religious Studies of "religionism," and of even "non-denominational, inter-axial faiths" or "philosophical anthropology," so as to make the study of religion "a fully secular, fully neutral discipline" [11]. Likewise, Donald Wiebe writes that the academic study of religion is "undermined" by "many of its practitioners who were committed both to the scientific study of religion and the maintenance of religious faith" ([12]. Of course, Wiebe, has a degree in theology and his appointment at Trinity College in Toronto is listed as being in Theology [13]. Thus it strikes one as surprising, at least on the surface, that he is one of the most persistent critics of what he believes is the non-scientific or anti-scientific study of religion, and he asserts that a "science of religion" will have to locate its "theories of religion" within what might be called an integrated causal model' of the sciences and consequently, will be reductionistic' in that they will attempt to explain 'the supernatural' naturalistically. All explanatory and theoretical accounts of religion within the Religious Studies framework, therefore, will have to fall within the same conceptual and causal framework used to explain all other elements and aspects of the natural and social worlds [14].

Fundamentally, such a perspective derives historically from exoteric or "exterior" Christianity (as distinct from esoteric or "interior" Christianity), that is, an anti-mystical perspective that emphasizes belief and that denigrates mysticism, but is converted 
into a modern "secular" insistence on "the same conceptual and causal framework used to explain all other elements and aspects of the natural and social worlds." Some aspects of the relationships between religious and secular heretic hunting are explored in Arthur Versluis's The New Inquisitions: Heretichunting and the Origins of Modern Totalitarianism, the point being that dynamics (like heretic-hunting) commonly associated with Western European forms of Christianity both Roman Catholic and Protestant sometimes are replicated in putatively secular environments [15].

An example of such replication of heretic-hunting in a secular environment is Daniel Dubuisson's The Western Construction of Religion: Myths, Knowledge, and Ideology [L'Occident et la religion: Mythes, science et idéologie], wherein he argues "admitting a priori that the intelligible transcends the sensible" "is an attitude incompatible with the aims of an authentic, well-founded scientific undertaking" [16]. According to Dubuisson, "the intelligible no less than the perceptible belongs to this world, and both are the issue of comparable historical processes." "Both are exactly situated on the same level, the human level" [17].

Dubuisson is overtly anti-mystical. For him, "mystic experience," "the direct, lived experience of the individual confronted with the dazzling revelation of a superior reality" is anathema because any assertion of a "transcendent level" of "lived, religious experience" "brings in its wake the indispensable but inadmissible epistemological corollary that the substratum of this experience escapes history, that it cannot be assigned to any of the domains (sociological, psychological, etc.) among which are distributed our knowledge and our explanations of human facts" [18] He extols "materialist thinkers," asserts the total hegemony of discursive reason and rejects any other model of knowledge than his own, which he deems "empirical" [19].

Dubuisson proceeds by presumptive assertion, a fallacious circularity in which he heaps invective on his opponents. Hence he claims that Mircea Eliade's work is a "metaphysico-political hodge-podge" and "ideological rubbish," "an incredible bric-a-brac, a pell-mell association of alchemy, yoga, tantrism, Gnosticism, Alexandrian Hermeticism" and other esoteric traditions, an "inadmissible amalgam," a "stupefying syncretism" of "rubbish," and so forth [20]. This barrage of attack-by-labeling has underneath it the presumption that Eliade's own terminology-for instance, often in quotation marks in Dubuisson's text, such terms as "secret knowledge," "mysteries," "myths," "supernatural beings," "sacred presence," "mystery of totality" - can all be dismissed gesturally, simply by repeating the same rejection in different vituperative forms [21].

In fact, Dubuisson's assertions are based upon a hidden assumption: the completeness of physical laws, based in the "objectivity" of old, classical science, which excludes the possibility "that the intelligible transcends the sensible". Dubuisson seems unaware of the existence of the Gödel theorem. Mathematics used in physics includes arithmetic, and thus, logically, physical theories should be subject to the findings of Gödel's theorems: a sufficiently rich system of axioms without internal contradiction is necessarily open (there will always be true results, but which cannot be proven), and therefore a rich enough closed system is necessarily contradictory. "Maybe we have to accept, after having reached the most thoroughly understanding level that science can provide, that certain aspects of the universe are still unexplained," writes the physicist Brian Greene. "Maybe we will have to accept that some of its features are due to a juncture, to chance, or even to some divine work" [22].

The transdisciplinary approach draws on a generalization of this gödelian aspect of nature. Every model of each level of reality is characterized by its incompleteness. The incompleteness of the general laws governing a given level of reality signifies that, at a given moment of time, one necessarily discovers contradictions in the theory describing the respective level: one has to assert A and non-A at the same time. The laws governing this level are just a part of the totality of laws governing all levels. And even the totality of laws cannot exhaust the entirety of reality: we have also to consider the subject and its interaction with the object, through the hidden third. Knowledge is forever open.

Of course, Dubuisson is more extreme in his efforts to reject all epistemological levels and to insist on a flat-earth view in which "there is no atemporal essence or supertemporal origin of religion," and in which there are only religious "structures of [institutional] power that situated it [religion] in the heart of the Church" [23]. Dubuisson rejects "all those (Platonists, Christians, esoterics, mystics) who subordinate the existence of this human world to 
principles that transcend it and to which religious facts' testify," in favor of "materialist thinkers, for whom there exists only a single world, subject to laws immanent in it" [24]. But even Wouter Hanegraaff, in following his former colleague Jan Platvoet, in effect argues against "a multiple-tier cosmology" in favor of a "one-tier cosmology" [25].

Unfortunately, "Western esotericism," which developed since the 1990s, has emerged as a sidestepping of fundamental issues, so much so that leading figures in the field are unable to define clearly what their subject even is. In Western Esotericism: A Guide for the Perplexed, Hanegraaff defines "esotericism" as "the academy's dustbin of rejected knowledge" that, although it is not "just a random collection of discarded materials without any further connection," presents "no such thing as a 'best example' of esotericism." Indeed, "there are no prototypical "esotericists." His externalist approach presents no clear definition of esotericism, and defines Western esotericism in a bewilderingly vague way as "characterized by a strong emphasis on specific worldviews and epistemologies that are at odds with normative post-Enlightenment intellectual culture" [26].

That the area putatively under study here, "Western esotericism," is so poorly described is not an accident, but rather, largely corresponds to the aforementioned more widespread attempt to limit all inquiry to materialistic, naturalistic, or physicalistic approaches to the study of religion. Such authors are attempting to reject from the study of "esotericism" precisely what is esoteric, that is to say, epistemological levels. Hence they attempt to argue against the very idea of esoteric religion as referring to an "inner" dimension that is "inaccessible to a normal scholar," the world "normal" here anathematizing any perspective other than a materialistic one-tier cosmology [27]. The bizarre coinages "religionism" or "religionist" (as pejoratives for those who disagree with such reductionistic approaches) indicate the profound methodological confusions at work here.

Authors like Dubuisson are radical externalists. They believe that "by definition" the scholar must remain removed from the object of inquiry-one must somehow remain radically external to what is being investigated. From this perspective, the scholarly subject "will always remain" divorced from the object under consideration. Subject and object here are conceived of in a thoroughly dualistic way that really does belong to the seventeenth or eighteenth centuries. Such a perspective is claimed to be "scientific." But in fact, radical externalism is very far from the era of quantum mechanics and of transdisciplinarity.

Externalist scholars base their work in an outdated view of science and an outdated view of reality. They are prisoners of the paradigm of simplicity, which was replaced by the paradigm of complexity. Classical realism was based on continuity, local causality, determinism and objectivity, while quantum realism is based upon discontinuity, a superposition principle of "yes" and "no," non-separability and indeterminism. Space-time itself appears as an anthropomorphic construction.

A fundamental problem with many of the scholars of religion concerning spirituality is in fact category error. When a scholar of religion insists on explaining spirituality with "the same conceptual and causal framework used to explain all other elements and aspects of the natural and social worlds," this is a category error. The dualistic division between subject and object is valid on one level, but not in the same way valid at another level, for instance, when we are considering interior spirituality, that is, modalities of being in which the subject and object are not so easily divided, indeed, in which subject and object may be united. Of course, in the manner of Dubuisson, one can reject mysticism out of hand, but that does not change the fact that alchemy or mysticism represent completely different epistemological and ontological categories than simplistic, outdated naturalist physicalism. In fact, externalist scholars attempt to eliminate the subject from their field of study. However, objectivity, set up as the supreme criterion of truth, has one inevitable consequence: the transformation of the subject into an object. The death of the subject is the price one has to pay for objective knowledge. As one important French philosopher asserted, the subject became just a word in a phrase [28].

\section{Transdisciplinarity and Consciousness}

Transdisciplinarity captures both quantum reality and the incompleteness of physical laws through the crucial notion of "spiritual information" [29]. A flow of spiritual information that coherently cuts across different levels of reality of the subject corresponds 
to the flow of natural information coherently cutting across different levels of reality of the object. The two flows are interrelated because they share the same zone of non-resistance. The hidden third is the transdisciplinary unifier of spiritual and natural information, but it cannot be reduced to either of them. The subject cannot be reduced to the object. Of course, spiritual information can't be measured by instruments like accelerators, voltmeters, microscopes or telescopes. But it can be experienced by the most complex instrument of measure: the human being in its interiority. The interior is as important as the exterior. The irreducible mystery of the world coexists with the wonders discovered by reason. The unknown enters every pore of the known, but without the known, the unknown would be a hollow word.

We are now at a transition point historically where not only the humanities but also the rest of the sciences need to go beyond the confines of physicalism and dualism, widening the scope of our vision and therefore understanding. A narrow reductive physicalism simply no longer is tenable, just as James W. Jones points out [30]. Consciousness, Jones remarks, may well be a "necessary element of the universe as we know it, perhaps on analogy to the constants of fundamental physics," a view amenable to Neoplatonic, Hindu, and Buddhist perspectives. As Jones puts it, contemplative insight "into the creative power of consciousness and its inseparability from everything we know, can be a window on a reality beyond that subject-object duality in which natural science and its offshoots in cognitive neuroscience are confined" [31].

In fact, interior spirituality is esoteric precisely because it includes dimensions transcending conventional subject-object divisions. In Magic and Mysticism, Versluis described esoteric or interior spirituality as existing on a spectrum [32]. To recapitulate: the union of subject and object characterizes the spectrum as a whole, but in different ways at each end, which are cosmological and metaphysical respectively. At the cosmological end one has magical traditions in which the subject seeks to affect or control the object through magical actions such as rituals. Here, subject and object are seen by the operator to be connected, but nonetheless clearly separated. More toward the middle of the spectrum are alchemical traditions in which the subject (the alchemical operator) and the object (the alchemi- cal Work) are difficult to separate. The alchemical practitioner works with herbs, minerals, or other substances, but also is himself being transmuted in the process. The subject transmutes the object, and the object transmutes the subject at the same time. At the other, metaphysical end of the spectrum, apophatic mysticism, neither subject nor object are differentiated in the conventional way but rather are transcended such that one has to employ the via negativa or language of negation to describe what is effectively self-other transcendence.

Here we are in a domain that calls for experiential confirmation. Christopher Bache observes that in such a domain confirmation does not come from "empirical research" alone, but also from experiential corroboration [33]. Under consideration here is "a kind of knowledge that can only be assessed, or perhaps that is best assessed, by persons who have undertaken the training designed to awaken this knowledge." Or to put it another way, as Bache continues, "History reminds us that those who were not willing to look through Galileo's telescope were not in a position to evaluate his evidence" [34].

It is exactly here that the emergent literature of transdisciplinarity has much to offer. Above all, it offers an empiricism that acknowledges multiple epistemological and ontological levels, and that recognizes the sophisticated nature of esoteric spirituality as the transcendence of subject-object division. This can be understood through the figure of what Nicolescu and others have termed the "hidden third" (tiers caché) and also through the logic of the included middle that is necessary for the movement of consciousness from one epistemological level to another. The hidden third constitutes "the zone of non-resistance between the object and the subject, and the zone of non-resistance between the levels of reality" [35]. Whereas physics is concerned with reality defined as resistance, or as what resists, the hidden third is non-resistance, hence bridging subject and object.

There are many possible examples of how to understand the hidden third with regard to art. In Platonic Mysticism, Versluis discusses these in detail, and gives some examples of paintings from the Hudson River School, a nineteenth-century American movement sometimes also called Luminism, because its artists feature different kinds of illumination in the paintings [36]. Light, in these works, is itself a character, highlighting and deepening the 
primeval landscapes often revealed in them. A painting like "View from Mount Holyoke, Northampton, Massachusetts, after a Thunderstorm-The Oxbow" (1836) by Thomas Cole (1801-1848) cannot be understood if it is approached as an object, for instance, if one were to undertake chemical analysis of its pigments. Although analysis through objectification can provide what we term exterior knowledge, our interior experience of the painting is of an entirely different kind.

When we look at the painting, there is on the one side the painting's objective beauty, and on the other our subjective experience of it. But these, the object (the painting) and the subject (the viewer) are joined by a hidden third, which is the relationship between the viewer and the painting. This experiential relationship is neither wholly objective nor wholly subjective, but partakes in both at once. It is hidden because it is created by our viewing of the image, and is not accessible from outside the relationship. Our experience of the painting is intimate and hidden from external or exoteric perspectives; and although of course it can be expressed to some extent, its intimacy and interiority mean it is always veiled to others.

So too, when we savor a great poem like W. B. Yeats's "Sailing to Byzantium," there is on the one side the poem's objective structured beauty, and on the other our subjective experience of it. And here too, our relationship to the poem can be described as the hidden third, our participation in its beauty to which we contribute too. Allow us to give some examples. "Sailing to Byzantium" begins with this stanza: "That is no country for old men. The young / In one another's arms, birds in the trees .... Caught in that sensual music all neglect / Monuments of unageing intellect. The first line invokes the realm of nature and sensuality, while the last compares it to the enduring "monuments of unageing intellect." And the final stanza begins with the startling lines "Once out of nature I shall never take / My bodily form from any natural thing." Of course we know what these words individually mean, but what makes them great poetry comes from their mysterious beauty as we intimately experience it ourselves.

When taken to refer to social phenomena, the word "religion" does not describe what we are alluding to here, and the word "spirituality" is more appropriate, because spirituality refers to the inte- rior realm of experience and meaning. The word "religious" might be more appropriate for describing repetitive practices like rituals that may lead to particular kinds of spiritual experience. Hence we could refer to "esoteric religion" in the sense that only a few engage in such practices in an extended way. But the word "spirituality" better suits introspection or interiority, the inner field for the transcendence of subject and object that marks our deep engagement with esoteric literature and art.

Multiple epistemologies are not only theoretically possible, they are necessary, as Kocku von Stuckrad points out in his The Scientification of Religion [37]. Stuckrad argues that scientific naturalism or physicalism ought not be seen as an "ultimate system of knowledge," but rather as one in a plurality of knowledge systems [38]. We are arguing along similar lines-that is, that there are multiple kinds of epistemologies, not only one. What is more, different kinds of knowing (of the subject) correspond to different levels of reality (of the object), and as Nicolescu puts it, "The transdisciplinary notion of levels of reality is incompatible with the reduction of the spiritual level to the level of the psyche, of the level of the psyche to the biological level," and so forth [39]. Reductionism, refusal to acknowledge, or erasure of the hidden third "in knowledge signifies a one-dimensional human being who has been reduced to cells, neurons, quarks, and elementary particles."

By contrast, a transdisciplinary approach that acknowledges multiple levels of reality and the transcendence of subject-object division through art, literature, philosophy, and religion moves us much closer to a unified theory of knowledge that overcomes the fragmentation of knowledge and of the human being implicit in so many of the approaches to religion we have referred to in this article. The sciences and the humanities are indeed on the brink of a new era, which will require leaving behind antiquated reductionistic and dualistic assertions that may apply at a lower level, but that do not apply to knowledge that in fact belongs to higher levels of reality.

Because of extraordinary national investments in quantum physics theories and experimentation over recent decades, great strides were made, demonstrating that earlier classical and relativistic models, while providing significant insights into the laws governing the cosmos, had to give way to newer models for understanding the nature of the cosmos. These new 
models overturned previous "common-sense" perspectives as theorists sought to unveil successively deeper and more hidden dimensions of the cosmos.

There are several fundamental realizations that have the potential to transform our understanding of spirituality. Among these are:

1. The realization that the observer, the active of observing, and that which is observed are intertwined. Already Werner Heisenberg had recognized "What we observe is not nature itself, but nature exposed to our method of questioning." Hence the purpose is not to disclose the real essence of phenomena, but only to track down ... relations between the multifold aspects of our experience [40]. In the older, dualistic model of physics, there was presumed to be a discrete observer separate from the observed event, and through the act of observation, objective rules or laws could be posited, and all of these were considered as separate. But the new models derived from the realization that such posited separation was in fact illusory. Subject and object were not separate, and in fact, might better be regarded not only as interwoven, but perhaps even as fundamentally connected.

2. This fundamental interconnection can also be witnessed in the non-local entwinement of object and object, as in "spooky action at a distance" (See for instance [41]. Quantum entanglement demonstrates that what we may think of as discrete and disconnected phenomena are connected at the quantum level. What appears to be valid on one level (separation of subject and object, or of object and object) is not valid on another.

3. Levels of being. The idea of a scale of being is of course very ancient in the West [42]. Theological literature also expressed the idea of a "scale of being" in an elaborate way, which corresponds, of course, to a scale of reality. The scale of Jacob (Genesis 28:10-12) is one famous example. There are many variants of the scale of Being, including for instance the Climax or Ladder of Divine Ascent of Saint John Climacus (c. 525606). There are thirty steps of the ladder, describing the process of theosis. The transdisciplinary resistance and non-resistance is well illustrated in the Ladder: the human being climbs the steps, which denote the ef- fort of human beings being to evolve from the spiritual point of view through the resistance to their habits and thoughts. In transdisciplinarity, "levels of being" means levels of the subject. The subject, as it deepens its knowledge in interiority, draws from different levels of reality of the object. "Understanding" in transdisciplinarity means the fusion of knowledge and being.

Recent research and publications clearly point toward the necessity of transdisciplinary approaches to the study of consciousness, particularly in the area of spirituality. We are thinking here of such works as Edward Kelly, Adam Crabtree, and Paul Marshall, Beyond Physicalism: Toward Reconciliation of Science and Spirituality (2015) and Imants Baruss and Julia Mossbridge, Transcendent Mind: Rethinking the Science of Consciousness (2016) [43]. Such books point the way toward more sophisticated epistemological approaches to the study of consciousness that take into account the multiple-tier perspectives implicit in and revealed by the past century of research in quantum mechanics and its applications in transdisciplinary methodologies. Horizons are opened in such works. We are on the brink of a new era of exploration, this time of inner consciousness. Such research can be empirical, scientific, and interior, not denying and rejecting interiority through presumptive assertion, but acknowledging and exploring the different levels and kinds of consciousness. This is the future.

\section{Conclusion}

The fundamental problem in studying spirituality is that the inner cannot be ignored, and cannot be converted to an object. One can pretend to jettison inward exploration with invented terms like "religionism," the aim of which is to attempt to render those who recognize the vital role of interiority as outré, "beyond the pale" of academia. But in reality, such efforts ignore and serve to obscure the very nature of the subject itself. Obviously, there is a place for studying the exterior, that is, biologically, socially, and cognitively driven aspects of religious behavior or phenomena. However, it is futile to pretend that interiority does not exist or is not a vital part of human consciousness. Transdisciplinarity acknowledges the importance not only of the object, but also of the subject, and further, recognizes the 
subtle and vital relationships between the two in the figure of the hidden third. A transdisciplinary model provides the basis for much more sophisticated theoretical and methodological approaches to the study of religion, ones that do not ignore but rather recognize interiority as valid, indeed, essential in understanding spirituality.

An underlying assumption in the hard sciences is that collectively, scientists are engaged in developing progressively more extensive and deeper descriptions and understanding of what is true and real. Understanding consciousness itself is part of this ongoing process-in fact, it could not take place at all without it. Consciousness applied to or investigating the nature of objects is extrospection; consciousness applied to or investigating the nature of itself is introspection. This distinction is akin to the ancient distinction, as understood in the medieval period as well, between physics and metaphysics. That is, the word "metaphysics" derives from the Greek words $\mu \varepsilon \tau a ́$ (metá) "beyond," and $\varphi u \sigma \iota \kappa a ́ ~(p h y s i k a ́$, "physics"). Traditionally, physics and metaphysics are not oppositional, but complementary.

We call for the development of much more sophisticated terminologies and conceptual transdisciplinary analytical frameworks that take into account interiority (spirituality) as well as exteriority (religion). As Alan Wallace has clearly articulated, scientific method and interiority are not in conflict, and in fact introspection complements extrospection [44]. A simplistic dualism coupled with attempts to crudely reject or ignore interiority and the subjective no longer works in the age of quantum theories coupled with much more nuanced experimental and mathematical understanding of the hidden aspects of the cosmos. That said, the next frontier is without doubt not outside us but within, in consciousness itself. We are clearly collectively moving toward a transdisciplinary, unified approach to knowledge both for the humanities and the sciences. This article is intended to point toward some foundational aspects of just such an approach. We are convinced that the great challenges of today can be resolved and that aheadgiven transdisciplinary approaches along the lines outlined here-is nothing less than a new Renaissance.

Author Contributions: Paper was written collaboratively by two authors.

Funding: This research received no external funding.
Conflicts of Interest: The authors declare no conflict of interest.

\section{References}

[1] Nicolescu, B., (2002). Manifesto of Transdisciplinarity. Karen-Claire Voss, trs. Albany: SUNY P.

[2] Nicolescu, B., (2015). From Modernity to Cosmodernity: Science, Culture, and Spirituality, Albany: SUNY P.

[3] Penrose, R., (2005). The Road to Reality: A Complete Guide to the Laws of the Universe, New York: Knopf.

[4] Wallace, Allan B., (2004). The Taboo of Subjectivity: Toward a New Science of Consciousness, New York: Oxford UP.

[5] Wallace, Allan B., (2004). The Taboo of Subjectivity: Toward a New Science of Consciousness, New York: Oxford UP.

[6] Martin, L. H. and Wiebe, D., (2014). Establishing a Beachhead: NAASR Twenty Years Later, at https://naasr.com/about-2, pdf available here: https://naasrreligion.files.wordpress.com/2014/01/ establishingabeachhead.pdf

[7] Drees, W., (2016). Existentialist Literature, Cognitive Science of Religion, and the Scientification of Religion, Zygon, 51(4), 833-834

[8] Nikkel, D., (2015). The Dualistic, Discarnate Picture that Haunts the Cognitive Science of Religion, Zygon 50(September 2015), 621-646.

[9] Peterson, Gregory R., (2010). Are Evolutionary/Cognitive Theories of Religion Relevant for Philosophy of Religion? Zygon, 45(3), 545-557.

[10] Slingerland, E., (2008). The Study of Religion in the Age of Cognitive Science. Journal of the American Academy of Religion, 76, 375411.

[11] Antes, Peter, Geertz, Armin, Warne, Randi Ruth, eds., (2008). New Approaches to the Study of Religion. Berlin: Walter de Gruyter.

[12] Wiebe, D., (2006). The Eternal Return All Over Again: The Religious Conversation Endures. Journal of the American Academy of Religion, 74(3), 674-696 [692-693].

[13] Wiebe, D., (1999). The Politics of Religious Studies: The Continuing Conflict with Theology in the Academy. New York: Palgrave.

[14] Wiebe, Donald, (2006) The Eternal Return All Over Again: The Religious Conversation Endures. Journal of the American Academy of Religion, 74(3), 674-696 [692-693]. 
[15] Versluis, A., (2006). The New Inquisitions: Heretichunting and the Origins of Modern Totalitarianism. New York: Oxford UP.

[16] Dubuisson, D., (1998), (2003). The Western Construction of Religion: Myths, Knowledge, and Ideology [L'Occident et la religion: Mythes, science et idéologie. Baltimore: Johns Hopkins UP.

[17] Dubuisson, Daniel, (1998) (2003). The Western Construction of Religion: Myths, Knowledge, and Ideology [L'Occident et la religion: Mythes, science et idéologie. Baltimore: Johns Hopkins UP.

[18] Dubuisson, Daniel, (1998) (2003). The Western Construction of Religion: Myths, Knowledge, and Ideology [L'Occident et la religion: Mythes, science et idéologie. Baltimore: Johns Hopkins UP.

[19] Dubuisson, D., (2006). Twentieth Century Mythologies: Dumézil, Lévy-Strauss, Eliade. London: Routledge.

[20] Dubuisson, D., (2006). Twentieth Century Mythologies: Dumézil, Lévy-Strauss, Eliade. London: Routledge.

[21] Dubuisson, D., (2006). Twentieth Century Mythologies: Dumézil, Lévy-Strauss, Eliade. London: Routledge.

[22] Greene, B., (2000). The Elegant Universe: Superstrings, Hidden Dimensions, and the Quest for the Ultimate Theory London: Vintage Series, Random House. Brian Greene, (2000) [edition cited] L'Univers elegant: Une revolution scientifique: $d$ l'infiniment grand à l'infiniment petit, l'unification de toutes les theories de la physique, trans. Céline Laroche. Paris: Robert Laffont.

[23] Dubuisson, D., (1998), (2003). The Western Construction of Religion: Myths, Knowledge, and Ideology L'Occident et la religion: Mythes, science et idéologie. Baltimore: Johns Hopkins UP.

[24] Dubuisson, D., (1998) (2003). The Western Construction of Religion: Myths, Knowledge, and Ideology [L'Occident et la religion: Mythes, science et idéologie. Baltimore: Johns Hopkins UP.

[25] Hanegraaff, W., (1995). Empirical Method in the Study of Esotericism. Method 85 Theory in the Study of Religion, 7(2), 99-129.

[26] Hanegraaff, W., (2013). Western Esotericism: A Guide for the Perplexed. London: Bloomsbury.

[27] Hanegraaff, W., (2013). Western Esotericism: A Guide for the Perplexed. London: Bloomsbury.

[28] Descombes, V., (2004). Le complément du sujet. Paris: Gallimard.

[29] Nicolescu, B., (2015). From Modernity to Cosmodernity: Science, Culture, and Spirituality. Albany: SUNY P.
[30] Jones, J. W., (2016). Can Science Explain Religion? New York: Oxford UP.

[31] Jones, J. W., (2016). Can Science Explain Religion?. New York: Oxford UP.

[32] Versluis, A., (2007). Magic and Mysticism: An Introduction to Western Esotericism. Lanham: Rowman Littlefield.

[33] Bache, C., (2000). Dark Night, Early Dawn: Steps to a Deep Ecology of Mind. Albany: SUNY P.

[34] Bache, C., (2000). Dark Night, Early Dawn: Steps to a Deep Ecology of Mind. Albany: SUNY P.

[35] Versluis, A., (2017). Platonic Mysticism: Contemplative Science, Philosophy, Literature, and Art. Albany: SUNY P.

[36] Nicolescu, B., (2015). From Modernity to Cosmodernity: Science, Culture, and Spirituality. Albany: SUNY P

[37] Stuckrad, Kocku von, (2014). The Scientification of Religion: An Historical Study of Discursive Change. Berlin: de Gruyter.

[38] Stuckrad, Kocku von, (2016). The Hybridity of Scientific Knowledge: A Response to Leonardo Ambasciano, in Zygon: Journal of Religion and Science, 51(4) at http://www.zygonjournal.org/issue2016_4.html [DOI: 10.1111/zygo.12305]. See also Versluis, Arthur (2006) The New Inquisitions. New York: Oxford UP.

[39] Nicolescu, B., (2015). From Modernity to Cosmodernity: Science, Culture, and Spirituality. Albany: SUNY P.

[40] Bohr, N., (1934). Atomic Theory and the Description of Nature. Cambridge. Cambridge UP. Heisenberg, Werner. (1958), Physics and Philosophy. New York: Harper.

[41] Lee, K.C., et al., (2011). Entangling Macroscopic Diamonds at Room Temperature, Science, 334(6060): 1253-1256; Juan Yin, et al. 2012. Quantum Teleportation and Entanglement Distribution Over 100kilometre Free-space Channels, in Nature, 488:185188. doi:10.1038/nature11332

[42] Lovejoy, A., (1934). The Great Chain of Being: A Study of the History of an Idea. Cambridge: Harvard UP.

[43] Baruss, I., and Mossbridge, J., (2016). Transcendent Mind: Rethinking the Science of Consciousness. Washington, D.C.: American Psychological Association. Edward Kelly, Adam Crabtree, and Paul Marshall. (2015), Beyond Physicalism: Toward Reconciliation of Science and Spirituality. Lanham: Rowman and Littlefield. 
[44] Wallace, A. B., (2010). Hidden Dimensions: The Unification of Physics and Consciousness. New York: Columbia UP. Wallace, Allan B., (2011), Contemplative Science: Where Buddhism and Neuroscience Converge. New York: Columbia UP.

\section{About the Authors}

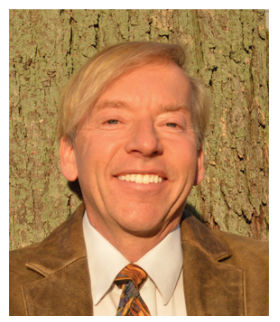

Dr. Arthur Versluis, Chair of the Department of Religious Studies and Professor in the College of Arts \& Letters at Michigan State University, holds a doctorate from the University of Michigan, Ann Arbor, and has published numerous books and articles. Among his many books are Platonic Mysticism (SUNY Press 2017), American Gurus (Oxford UP, 2014), Magic and Mysticism: An Introduction to Western Esotericism(Rowman Littlefield, 2007), Restoring Paradise: Esoteric Transmission through Literature and Art (SUNY: 2004); The Esoteric Origins of the American Renaissance (Oxford UP: 2001); Wisdom's Book: The Sophia Anthology, (Paragon House, 2000); Wisdom's Children: A Christian Esoteric Tradition (SUNY: 1999); and American Transcendentalism and Asian Religions (Oxford UP, 1993). Versluis is editor of JSR: Journal for the Study of Radicalism. He is the founding president of the Association for the Study of Esotericism.

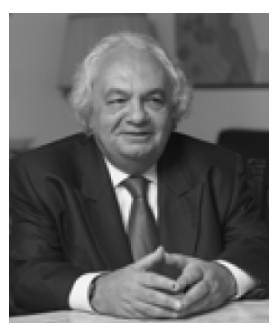

Dr. Basarab Nicolescu, is a theoretical physicist at the Centre National de la Recherche Scientifique (CNRS), Paris, France. Professor at the Babes-Bolyai University, Cluj-Napoca, Romania. Member of the Romanian Academy. Professor Extraordinary at the School of Public Leadership, Stellenbosch University, South Africa. Founding member of ISSR. President-Founder of the International Center for Transdisciplinary Research and Studies (CIRET). Founder and Director of the Transdisciplinarity Series, Rocher Editions, Monaco, of the Romanians in Paris Series, Oxus Editions, Paris and of the Science and Religion Series, Curtea Veche, Bucharest (in collaboration with Magda Stavinschi). A specialist in the theory of elementary particles, Basarab Nicolescu is the author of
130 articles in leading international scientific journals, has made numerous contributions to science anthologies and participated in several dozen French radio and foreign multimedia documentaries on science. Basarab Nicolescu is a major advocate of the transdisciplinary reconciliation between Science and the Humanities. He published many articles on the role of science in the contemporary culture in journals in USA, France, Romania, Italy, United Kingdom, Brazil, Argentina and Japan. His books include : Hidden Third, Quantum Prose, New York, 2016; From Modernity to Cosmodernity - Science, Culture, and Spirituality, State University of New York (SUNY) Press, New York, 2014, Manifesto of Transdisciplinarity, State University of New York (SUNY) Press, New York, 2002; Science, Meaning and Evolution - The Cosmology of Jacob Boehme, Parabola Books, New York, 1991. He edited Transdisciplinarity - Theory and Practice, Hampton Press, Cresskill, New Jersey, 2008. 